\title{
Seismic Design of Offshore Structures under Simplified Pulse-Like Earthquakes
}

\author{
Foteini Konstandakopoulou ${ }^{1}\left(\mathbb{D}\right.$, George Papagiannopoulos ${ }^{1}$ (D), Nikos Pnevmatikos ${ }^{2}$, \\ Konstantinos Evangelinos ${ }^{3}$, Ioannis Nikolaou ${ }^{4}$ and George Hatzigeorgiou $1, * \mathbb{D}$ \\ 1 School of Science and Technology, Hellenic Open University, GR-26335 Patras, Greece; \\ konstantakopoulou.foteini@ac.eap.gr (F.K.); papagiannopoulos@eap.gr (G.P.) \\ 2 Department of Civil Engineering, University of West Attica, GR-12241 Athens, Greece; pnevma@uniwa.gr \\ 3 Department of Environment, University of the Aegean, GR-81100 Mytilene, Greece; kevag@aegean.gr \\ 4 Department of Environment Engineering, Democritus University of Thrace, GR-67100 Xanthi, Greece; \\ inikol@env.duth.gr \\ * Correspondence: hatzigeorgiou@eap.gr; Tel.: +30-2610-367-769
}

Received: 23 September 2020; Accepted: 25 November 2020; Published: 26 November 2020

check for updates

\begin{abstract}
Oil and gas offshore structures are essential infrastructures which are subjected to several categories of environmental loads such as wave and wind actions. These loads commonly designate the structural design of offshore platforms. Additionally, several offshore platforms are founded in earthquake-prone areas and the design of them is intensely affected by seismic ground motions. To be sure, various investigations have studied the earthquake response of offshore structures under the action of far-field seismic events. However, the inelastic behavior of platforms under the action of simple pulses has not been examined yet, where the latter loads can successfully simulate near-fault earthquakes. This work investigates, for the first time to our knowledge, the dynamic inelastic response of offshore platforms subjected to triangular, exponential, sinusoidal, and rectangular pulses. Thus, three-dimensional offshore structures are examined also considering the dynamic soil-pile-platform interaction effects, satisfying all the pertinent provisions of European Codes and taking into account geometric and material nonlinearities as well as the effects of the different angles of incidence of seismic waves on the overall/global response of offshore platforms.
\end{abstract}

Keywords: offshore platforms; seismic loads; simplified pulses; geometric nonlinearities; material nonlinearities; angle of incidence of seismic waves

\section{Introduction}

Offshore structures have been founded in different locations worldwide where the most common type of them is the offshore jacket type [1]. Protecting the reliability of Offshore Jacket Platforms (OJP) in earthquake-prone areas is an essential condition. Formerly, examination of OJP usually focused on ocean-wave effects while the examination of dynamic inelastic behavior due to strong ground motions seems to be rare. This might be due to the location of OJP, which are generally subjected to non-earthquake loads such as wave and wind actions. Nowadays, about 7000 offshore structures have been constructed worldwide where about 2500 are used for more than 25 years [2]. It is evident, therefore, that there are many OJP that are operated beyond their lifespan, while for other newer offshore platforms their operation life should be lengthened. Particularly for OJP that are located in earthquake-prone areas, their strength, stability, and behavior have been studied comprehensively [3-9]. More specifically, Chen et al. [3] examined the modeling of radiation damping for soil-platform systems, and El-Din and Kim [4] developed a method for life cycle cost estimation for offshore jacket platforms under seismic loads. Additionally, the seismic vulnerability of jacket-type offshore structures was 
investigated by Jahanitabar and Bargi [5] using fragility curves and considering the effects of ageing and deterioration. Konstandakopoulou et al. [6,7] examined the seismic behavior of offshore platforms under real records that have been recorded near the seismic faults. Elsayed et al. [8] executed a nonlinear progressive collapse analysis for the reliability assessment of an offshore platform. Furthermore, the seismic vibration control of an offshore jacket platform was investigated by Som and Das [9]. Moreover, Park et al. [10] examined the seismic response analysis of offshore platforms using the modal analysis and substructure methods, while Ajamy et al. [11] presented an analytical approach to develop seismic fragility curves of an existing jacket-type offshore platform in the Persian Gulf. Additionally, Zarrin [12] focused on the sources of the uncertainty considerably affecting the seismic response of platforms, and Abyani et al. [13] quantitatively investigated the effects of the sample size of records on the seismic performance of these structures. Lotfollahi-Yaghin et al. [14] investigated the efficiency of a tuned liquid damper in controlling the dynamic responses of offshore jacket-type platforms under earthquake excitation.

It should be mentioned that for the mainstream literature that examines the seismic response of offshore platforms, the pertinent research is concentrated on the far-field earthquakes while only a small number of works have investigated the response of OJP subjected to near-fault seismic ground motions [7]. It is noteworthy that near-fault seismic ground motions are characterized by a pulse-type excitation [15-17]. Considering this particularity, various studies have examined simple pulses for the seismic analysis of systems and structures, e.g., [17], where sinusoidal pulses are used to evaluate the response of ground medium near canyons considering several shapes and ground conditions. Furthermore, Zhao and Valliappan [18] adopted sinusoidal pulses to examine the earthquake response of nuclear power plants.

To the best of the authors' knowledge, the application of simple pulses to simulate near-fault earthquakes for the case of offshore jacket platforms have not yet been examined. To bridge this gap, this study investigates, for the first time, the nonlinear response of offshore jacket platforms under the action of simple ground motion pulses (i.e., triangular, exponential, sinusoidal and rectangular pulse waveforms) corresponding to intense near-fault earthquakes. Two different approaches are materialized where the first considers the effects of dynamic pile-soil-platform interaction and the second adopts the rigid-soil medium assumptions. This study focuses on the seismic performance of OJP, investigating their maximum response in terms of displacements and base shear. Additionally, the influence of geometric nonlinearities on the platform response is examined. Finally, this work provides helpful ideas and conclusions for forthcoming investigations.

\section{Simplified Pulse-Type Ground Motions}

This paper concentrates on simple pulses simulating near-fault earthquakes such as triangular, exponential, sinusoidal, and rectangular pulses. One can consult the work of Konstandakopoulou and Hatzigeorgiou [17] for more information about the application of these pulses in Single-DegreeOf-Freedom systems. The examining of cases could provide helpful conclusions about the intense earthquake response of offshore structures under the action of near-fault earthquakes. To be compatible with the design process (see Section 3), the peak ground acceleration (PGA) for these pulses is equal to $0.5 \mathrm{~g}$.

Thus, triangular waveforms are investigated here to simulate intense ground motions. Figure 1 shows the ground kinematic parameters (displacement, velocity, and acceleration) for the case of triangular waveforms. 


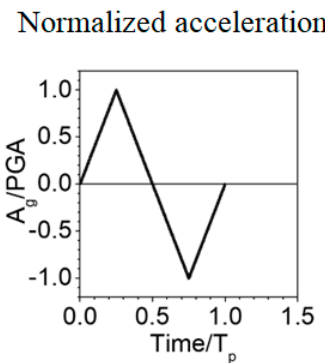

Normalized velocity

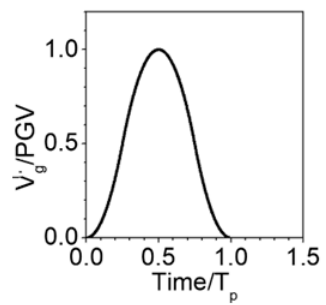

Normalized displacement

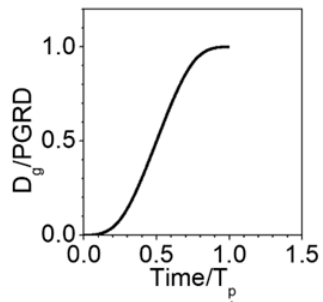

Figure 1. Triangular waveform.

Concerning the first-half-part of this pulse, the ground acceleration, $A g(t)$, is given by:

$$
\begin{gathered}
A_{g}(t)=P G A\left(\frac{4 t}{T_{p}}\right) \text { for }\left(0 \leq t \leq \frac{T_{p}}{4}\right) \\
A_{g}(t)=P G A\left(\frac{2\left(T_{p}-2 t\right)}{T_{p}}\right) \text { for }\left(\frac{T_{p}}{4}<t \leq \frac{T_{p}}{2}\right)
\end{gathered}
$$

whereas similar expressions can be defined for the second-half.

Furthermore, one exponential pulse with a complete cycle is investigated. The pulse period, $T_{p}$, or the corresponding circular frequency, $\omega_{p}$, defines the seismic load features. Figure 2 shows the loading time-history for acceleration, velocity, and displacement of ground motion, for this exponential waveform.

Normalized acceleration

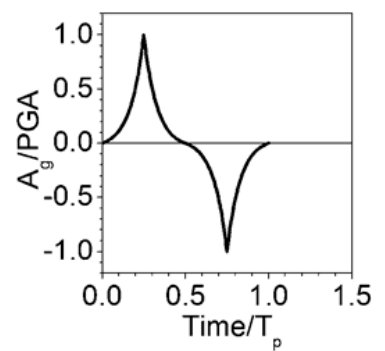

Normalized velocity

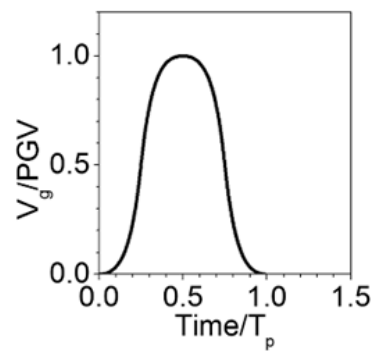

Normalized displacement

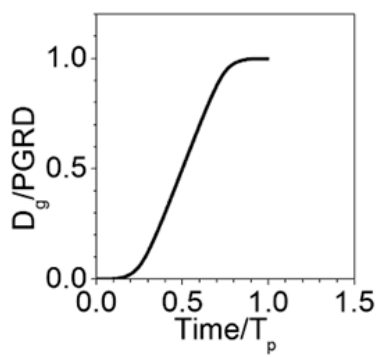

Figure 2. Exponential waveform.

Regarding the first-half of this pulse, the ground acceleration, $A g(t)$, is given by:

$$
\begin{aligned}
& A_{g}(t)=P G A\left(\frac{1-\exp \left(4 \pi t / T_{p}\right)}{1-\exp (\pi)}\right) \text { for }\left(0 \leq t \leq \frac{T_{p}}{4}\right) \\
& A_{g}(t)=P G A\left(\frac{1-\exp \left(4 \pi\left(T_{p} / 2-t\right) / T_{p}\right)}{1-\exp (\pi)}\right) \text { for }\left(\frac{T_{p}}{4}<t \leq \frac{T_{p}}{2}\right)
\end{aligned}
$$

whereas similar expressions can be defined for the second-half of this simplified exponential waveform. Furthermore, sinusoidal pulses also are investigated where ground acceleration, $A g(t)$, is given by:

$$
A_{g}(t)=P G A \sin \left(\frac{2 \pi t}{T_{p}}\right)
$$

Figure 3 shows the corresponding sinusoidal waveforms in terms of displacement, velocity, and acceleration. 
Normalized acceleration

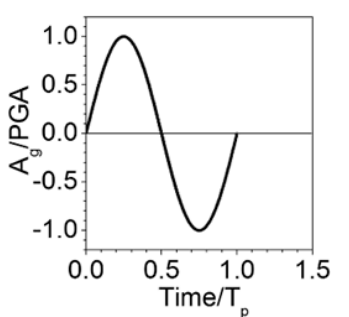

Normalized velocity

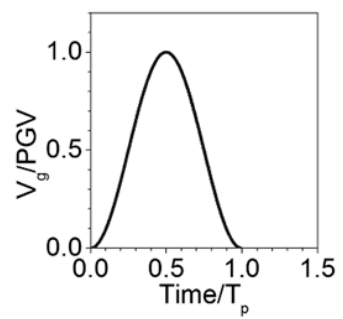

Normalized displacement

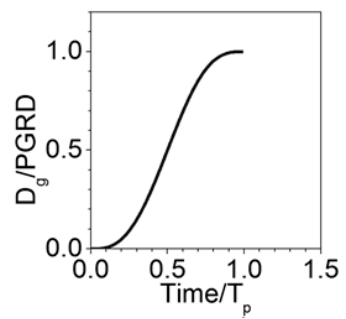

Figure 3. Sinusoidal waveform.

Finally, Figure 4 depicts rectangular waveforms in terms of ground acceleration, ground velocity, and ground displacement time histories.

Normalized acceleration

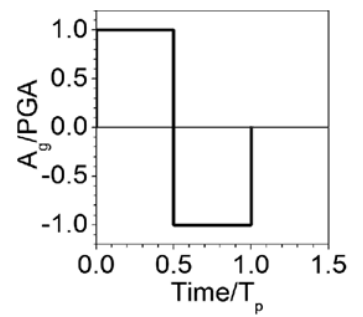

Normalized velocity

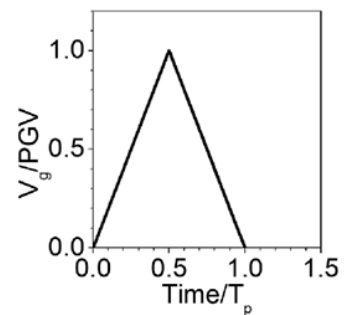

Normalized displacement

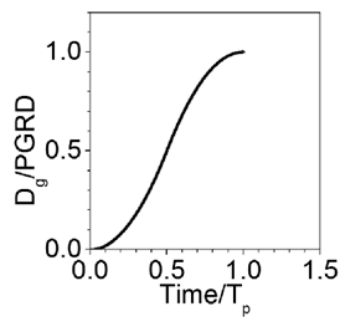

Figure 4. Rectangular waveform.

More specifically, the ground acceleration, $A g(t)$, for the simplified rectangular waveform of Figure 4 is given by:

$$
A_{g}(t)=|P G A| \quad \text { for }\left(0 \leq t \leq T_{p} / 2\right), \quad A_{g}(t)=-|P G A| \quad \text { for }\left(T_{p} / 2<t \leq T_{p}\right)
$$

The above-mentioned pulses can successfully simulate near-fault seismic records that have been noted close to seismic faults $[19,20]$, despite their simplicity. Adopting the sinusoidal waveform, for example, one can describe the Lucerne Station during Landers' Earthquake record (28/6/1992). Figure 5 shows the time history of the ground velocity as well as the corresponding spectral velocity.

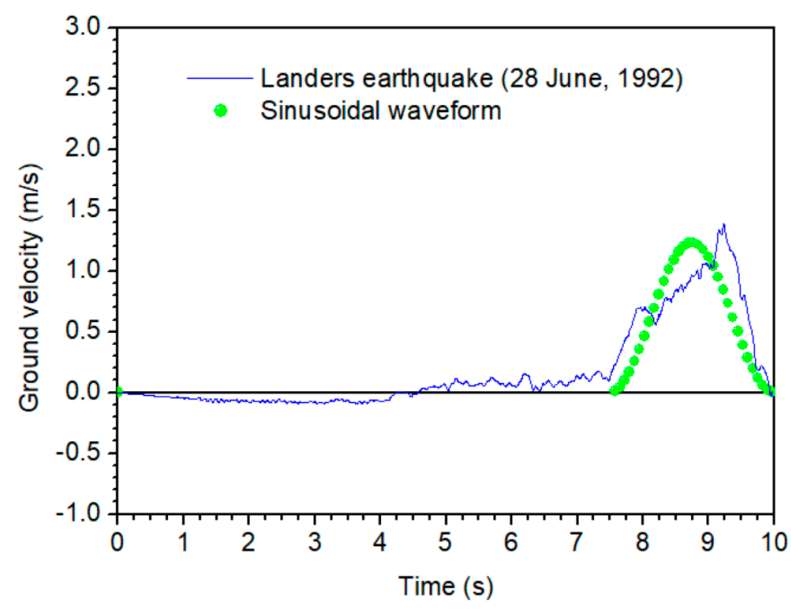

Figure 5. Cont. 


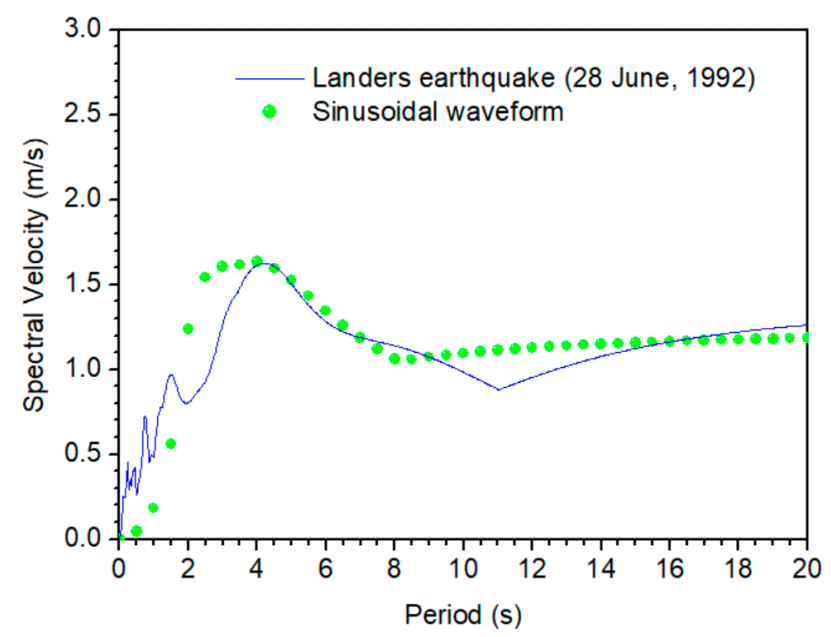

Figure 5. Landers' earthquake (28 June 1992): sinusoidal waveform simulation.

It is worth noticing that the adopted simplified waveforms can sufficiently describe real near-fault earthquakes since they efficiently follow the ground motions and their spectral counterparts. It also is worth noticing that there are many methods for the simulation of near-fault ground motions using specific waveforms. Baker [21], for example, proposed an effective method for quantitatively identifying ground motions containing strong velocity pulses, which was based on wavelet analysis. Additionally, Champion and Liel [22] quantified the effects of seismic pulses on the collapse risk of buildings through incremental dynamic analysis. He and Agrawal [23] proposed an analytical approach for pulse-like near-fault earthquakes for a systematic design and assessment of seismic protective systems. Finally, Christidis et al. [24] and Pnevmatikos and Hatzigeorgiou [25] examined pulse-like ground motions to assess the seismic behavior of building structures. The proposed study, however, does not focus on the simulation methodologies of real seismic records with pulses, rather it concentrates on the linear and nonlinear responses of offshore structures under the action of simplified waveforms.

Concluding this section, Figure 6 depicts the normalized ground acceleration of the simplified pulses examined in this study [17].
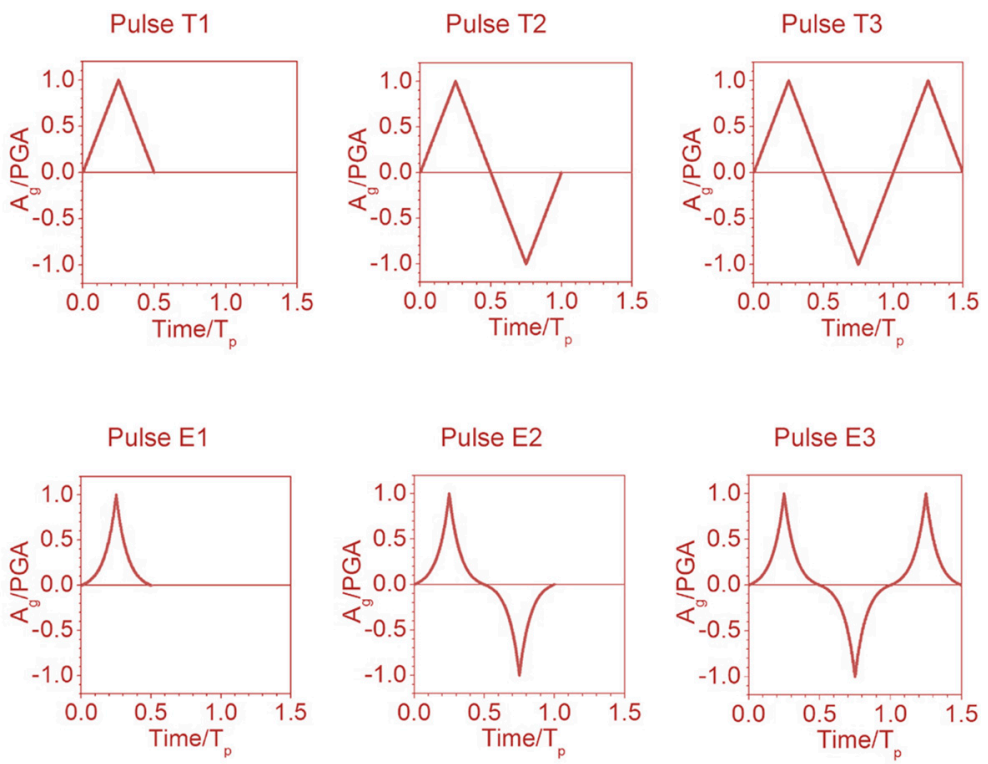

Figure 6. Cont. 

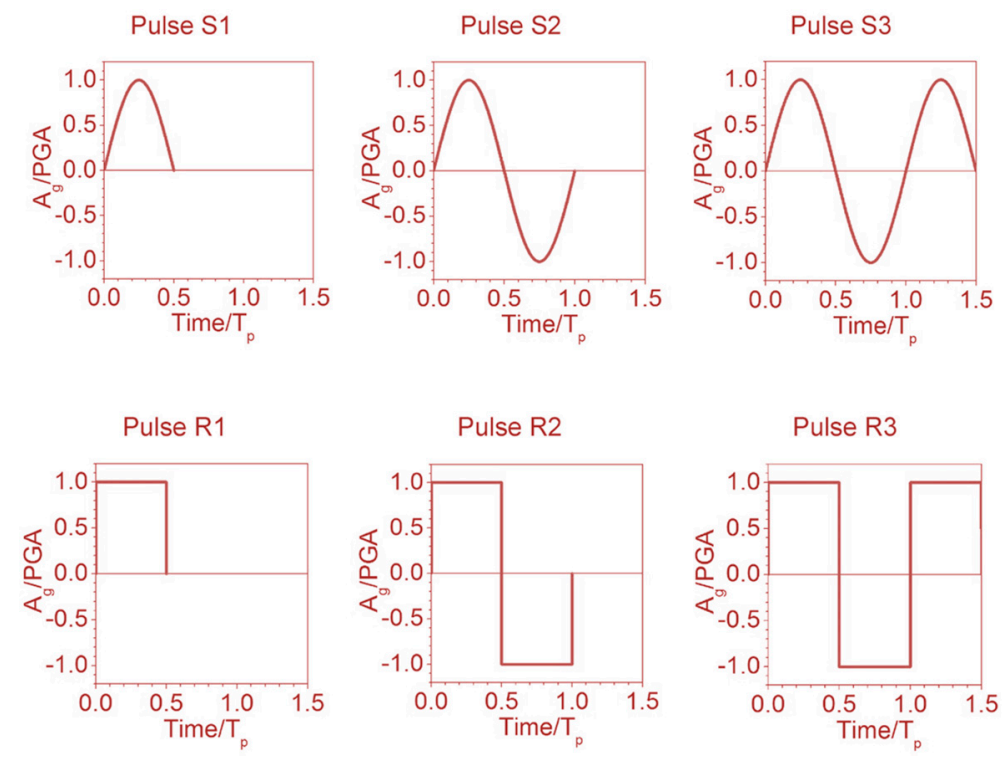

Figure 6. Normalized ground acceleration of simplified waveforms examined in this study [17].

\section{Offshore Jacket Platforms}

Various types of offshore platforms for the extraction of oil/gas have been constructed to date where the most common type (about $95 \%$ of total cases) is the Offshore Jacket Platforms (OJP) [6]. The basic elements of an OJP are deck, jacket (which corresponds to a bracing system for the piles), and foundation (piles). The total height of an OJP is the sea depth plus the design altitude of sea waves (which is about fifteen meters). The design of an OJP considers many loads and loading combinations such as vertical loads (self-weight, the weight of production and exploration facilities), environmental loads (waves, wind and seismic loads, temperature differences), and impacts (icebergand/or ship-percussion).

During this investigation, two OJP models are examined using Ruaumoko seismic inelastic finite element software [26]. Ruaumoko is used here taking into account that it can effectively model the post-buckling behavior of braces and the dynamic nonlinear soil-pile-platform interaction. Figure $7 \mathrm{a}$ depicts the 3-D finite element model of the examined offshore platform, ignoring the soil flexibility, i.e., assuming rigid soil conditions-Model I.

Additionally, another computational model, Model II, has been developed to consider the influence of soil flexibility on platform seismic behavior. Thus, Figure $7 \mathrm{~b}$ shows the pile-platform model where the foundation piles have been modeled using nonlinear beam-column finite elements. Furthermore, Figure 7c focuses on the modeling of the soil area close to piles using nonlinear dashpots and springs. Regarding the soil-pile models (see Figure 7c), it also is assumed that the soil-springs behave as a no-tension material following the Ramberg-Osgood hysteresis model [27]. The interface between surrounding soil and the pile is modeled using API (American Petroleum Institute) [28] suggestions for nonlinear spring and dashpot elements, while for the modeling of them the Boulanger et al. approach is obtained [29]. Considering both Models I-II, the structural members are beam-column finite elements with tubular cross-sections. Braces are modeled using the Remennikov-Walpole hysteresis approach [30], while all other members, i.e., piles, columns and beams are modeled utilizing the Al-Bermani hysteresis approach [31]. Figure 8 shows the cyclic responses using these hysteresis models. Finally, Table 1 shows the dimensions (external diameter/thickness) of steel tubular/pipe members of the platforms under consideration. 
(a)

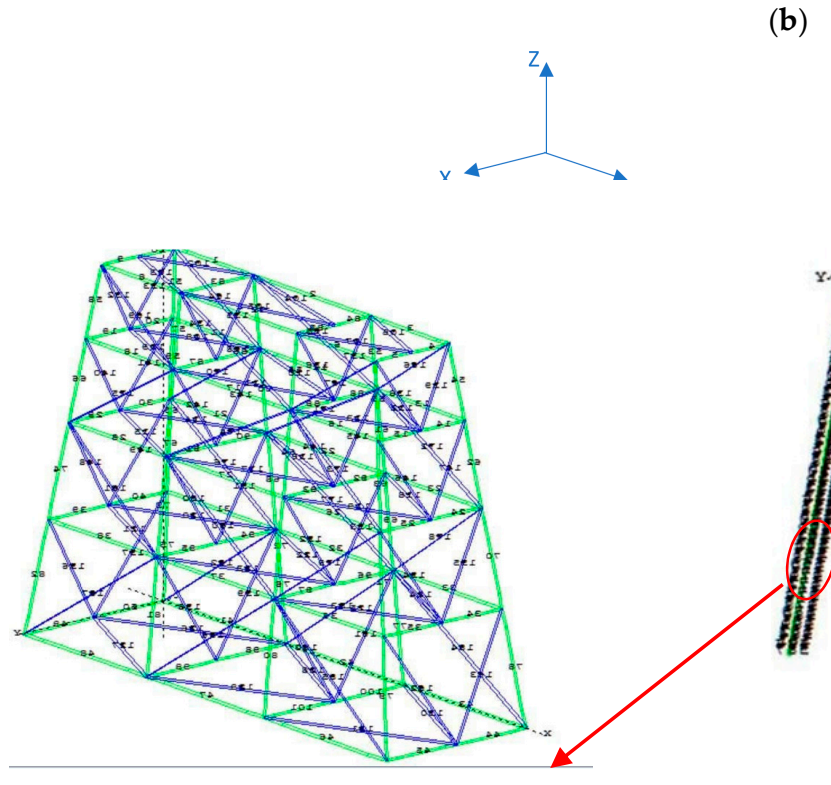

(c)

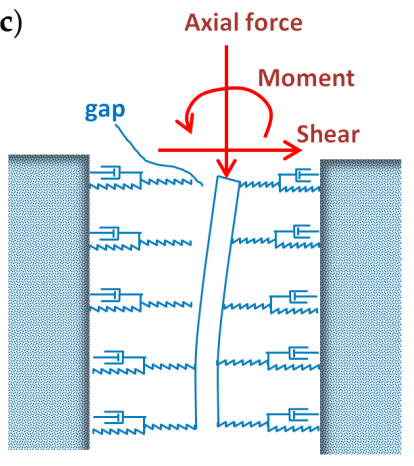

Figure 7. Finite element model of OJP: (a) Fixed platform assuming rigid soil-Model I, (b) Soil-pile-structure system for deformable soil-Model II, (c) Nonlinear model of soil-pile system-Model II.

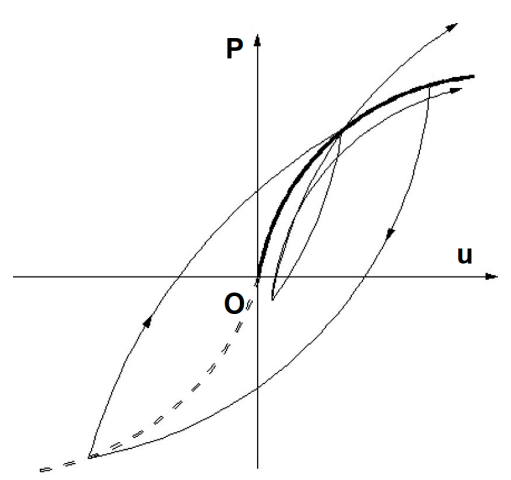

(a) Ramberg-Osgood model [27]

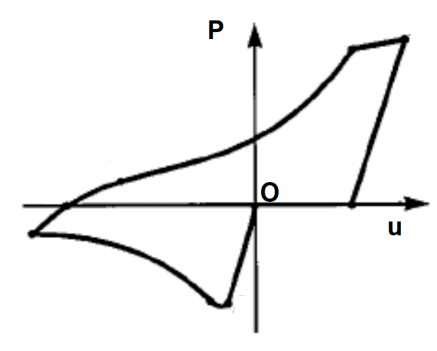

(b) Remennikov-Walpole model [30]

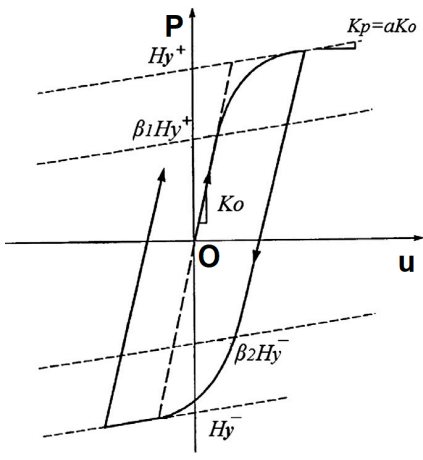

(c) Al-Bermani model [31]

Figure 8. Hysteresis models for: (a) Soil medium, (b) Braces, and (c) Piles, columns, and beams. 
Table 1. Cross-sections of platforms' tubular steel members.

\begin{tabular}{ccc}
\hline Members & Storey & $\begin{array}{c}\text { Circular Cross-Sections-ext. } \\
\text { Diameter } \times \text { Thickness [mm] }\end{array}$ \\
\hline \multirow{3}{*}{ Columns } & 0 & $110.0 \times 5.0$ \\
& 1 & $110.0 \times 5.0$ \\
& 2 & $90.0 \times 4.0$ \\
Beams & 3 & $90.0 \times 4.0$ \\
& 4 & $75.0 \times 4.5$ \\
& 0 & $75.0 \times 4.5$ \\
Braces & 2 & $80.0 \times 4.2$ \\
& 3 & $55.0 \times 4.0$ \\
& 4 & $55.0 \times 2.5$ \\
\hline & 0 & $55.0 \times 2.5$ \\
& 1 & $60.0 \times 2.2$ \\
& 3 & $50.0 \times 2.6$ \\
& 4 & $50.0 \times 2.2$ \\
\hline
\end{tabular}

\section{Selected Results}

Here, selected results from the linear and nonlinear dynamic response of offshore jacket structures under consideration, which are subjected to the action of pulse-type ground motions, are provided and critically discussed. It should be mentioned that the elastic case corresponds to the linear elastic behavior for both structure and soil-pile system, while the inelastic case has to do with the inelastic behavior for both structure and soil-pile system.

\subsection{Linear Analysis}

Here, the linear elastic response of OJP is examined. To be complete, Table 2 shows the first twenty eigenfrequencies, while Figure 9 depicts them in a diagram, for both models of soil consideration (rigid and flexible).

Table 2. Natural frequencies and periods for the first twenty eigenvalues

\begin{tabular}{ccccc}
\hline & \multicolumn{2}{c}{ Rigid-Soil Assumption } & \multicolumn{2}{c}{ Soil-Pile-Structure System } \\
\hline Eigenvalue & $\begin{array}{c}\text { Natural Frequency } \boldsymbol{\omega}_{\mathbf{n}} \\
(\mathbf{r a d} / \mathbf{s})\end{array}$ & $\begin{array}{c}\text { Period } \mathbf{T}_{\mathbf{n}} \\
\mathbf{( s )}\end{array}$ & $\begin{array}{c}\text { Natural Frequency } \boldsymbol{\omega}_{\mathbf{n}} \\
\mathbf{( r a d / s )}\end{array}$ & $\begin{array}{c}\text { Period } \mathbf{T}_{\mathbf{n}} \\
(\mathbf{s})\end{array}$ \\
\hline 1 & 3.199 & 1.964 & 2.675 & 2.349 \\
2 & 3.572 & 1.759 & 3.154 & 1.992 \\
3 & 4.488 & 1.400 & 3.666 & 1.714 \\
4 & 8.470 & 0.742 & 4.217 & 1.490 \\
5 & 9.587 & 0.655 & 6.397 & 0.982 \\
6 & 11.278 & 0.557 & 9.111 & 0.690 \\
7 & 12.837 & 0.489 & 9.475 & 0.663 \\
8 & 13.729 & 0.458 & 12.020 & 0.523 \\
9 & 14.118 & 0.445 & 13.407 & 0.469 \\
10 & 16.148 & 0.389 & 14.771 & 0.425 \\
11 & 16.776 & 0.375 & 15.431 & 0.407 \\
12 & 16.845 & 0.373 & 15.943 & 0.394 \\
13 & 16.936 & 0.371 & 16.002 & 0.393 \\
14 & 17.059 & 0.368 & 16.530 & 0.380 \\
15 & 17.097 & 0.367 & 16.474 & 0.381 \\
16 & 18.121 & 0.347 & 17.238 & 0.364 \\
17 & 20.207 & 0.311 & 18.617 & 0.337 \\
18 & 20.603 & 0.305 & 19.252 & 0.326 \\
19 & 21.068 & 0.298 & 19.340 & 0.325 \\
20 & 21.124 & 0.297 & 20.050 & 0.313 \\
\hline
\end{tabular}




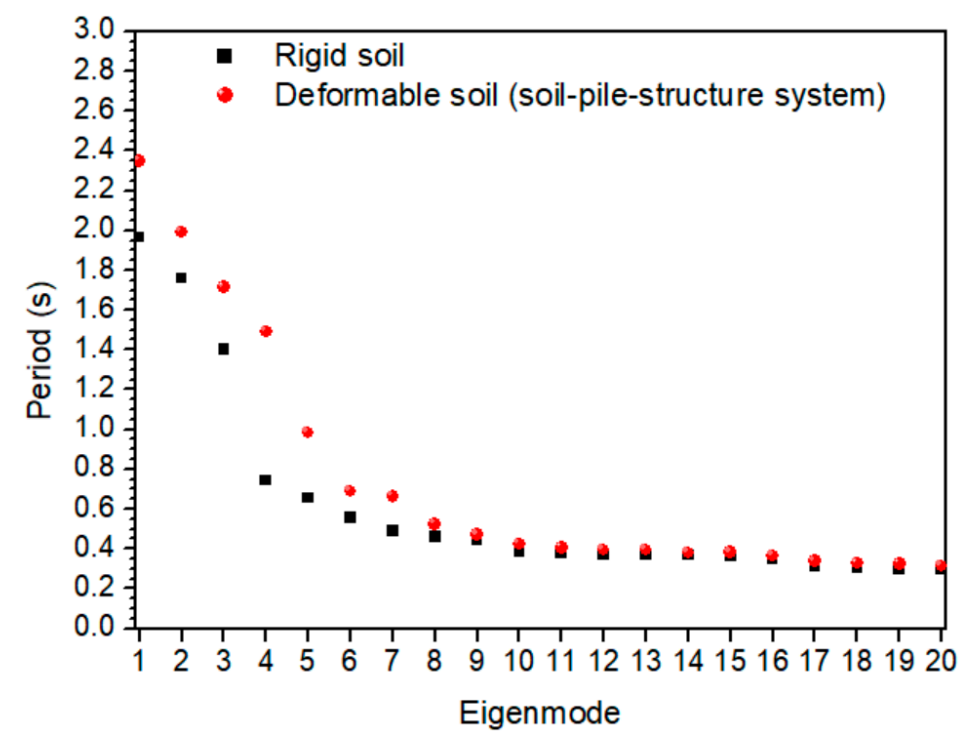

Figure 9. Eigenperiods of an offshore platform assuming rigid and deformable soil.

As it is expected, the pile-soil-platform system is more flexible in comparison with the rigid-soil model where the eigenperiods of the latter appear to be lower than the counterparts of the former.

The maximum horizontal displacement for the deck of the OJP, assuming rigid-soil conditions, is shown in Figures 10-13. More specifically, this offshore platform model is examined under the action of the whole gamut of waveforms for several values of frequencies, from 0.6 to $100.0 \mathrm{rad} / \mathrm{s}$, i.e., for a pulse-period ranging from 0.063 to $10.5 \mathrm{~s}$. Taking into account that Figures 10-13 depict the linear elastic response of the platforms under consideration, the vertical axis of these diagrams corresponds to the normalized value of the maximum displacement, i.e., maximum structural-maximum soil displacement.

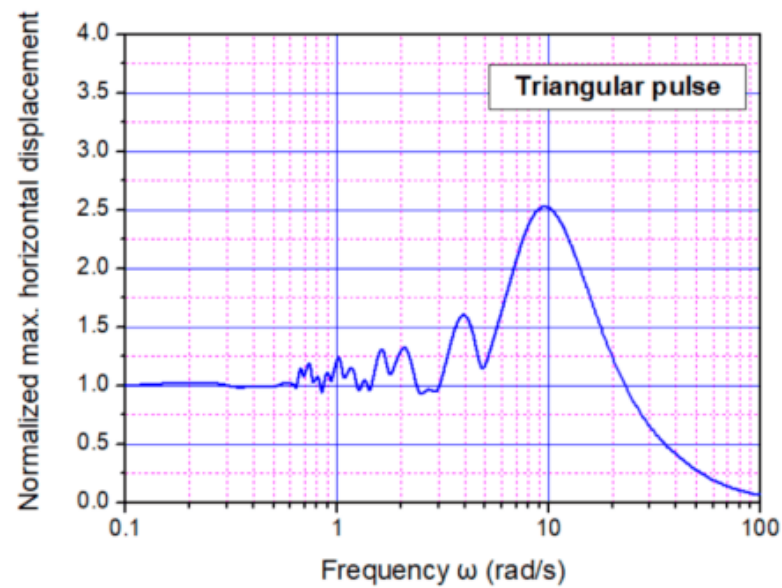

Figure 10. Normalized maximum displacement for fixed-base OJP under a triangular pulse. 


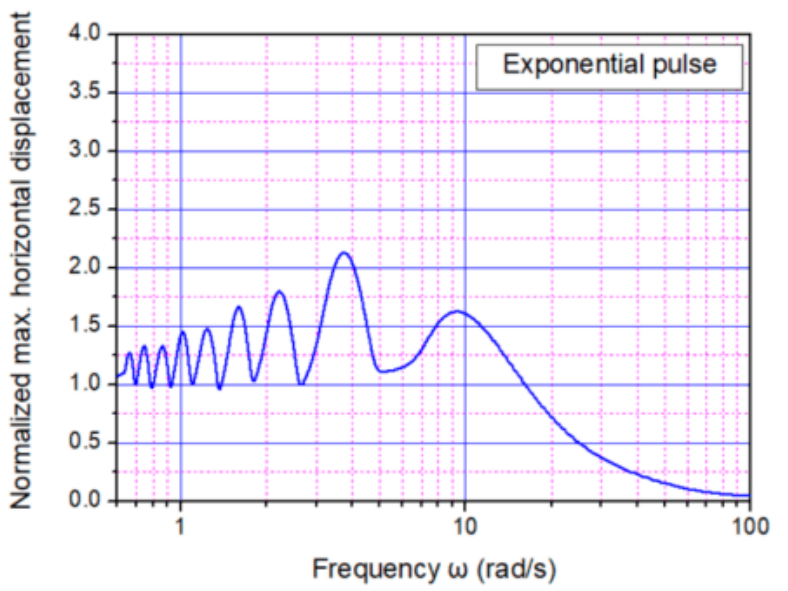

Figure 11. Normalized maximum displacement for fixed-base OJP under exponential pulse.

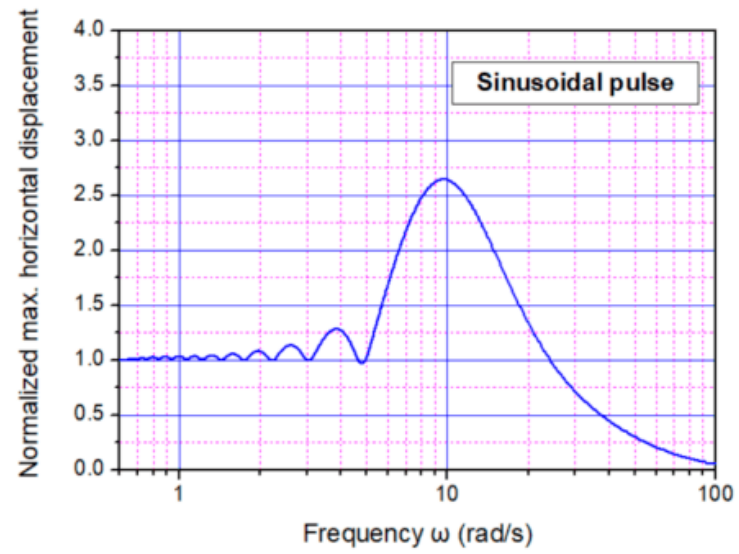

Figure 12. Normalized maximum displacement for fixed-base OJP under sinusoidal pulse.

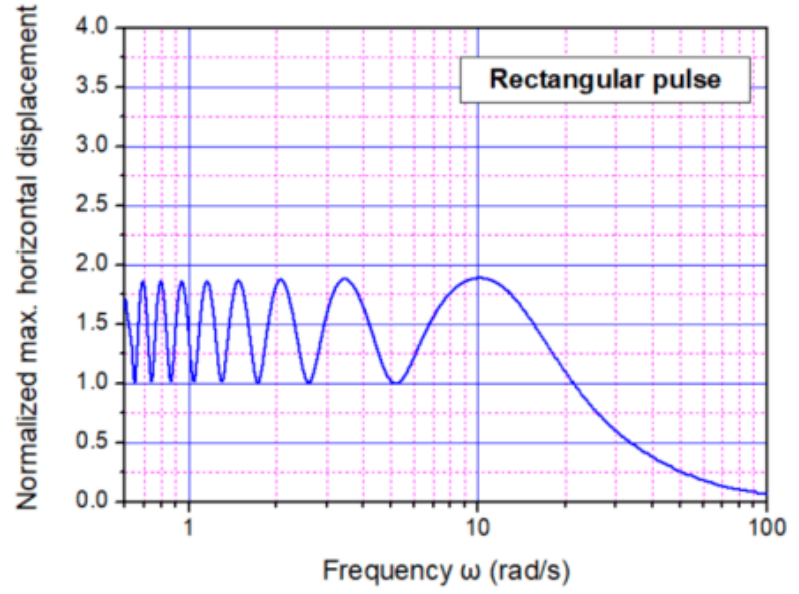

Figure 13. Normalized maximum displacement for fixed-base OJP under rectangular pulse.

It is obvious that these simple pulses lead to different responses between themselves. A rectangular waveform, for example, leads with numerous peaks with identical intensity for various loading frequencies. Conversely, sinusoidal waveforms appear to have a discrete peak value for a specific loading frequency. The load frequency $\omega=10 \mathrm{rad} / \mathrm{s}$ appears to be critical for any pulse-type under consideration. This is consistent with the eigenvalue analysis since the fifth eigenmode, with $\omega_{n, 5}$ $=9.587 \mathrm{rad} / \mathrm{s}(\approx 10 \mathrm{rad} / \mathrm{s})$, corresponds to the most critical vibration mode with about $75 \%$ modal participation mass. 
Finally, Figure 14 shows the dynamic behavior of OJP, for both rigid and flexible soil conditions, considering the aforementioned critical load frequency, $\omega=10 \mathrm{rad} / \mathrm{s}$, and for maximum peak ground acceleration, PGA, equal to $1.0 \mathrm{~g}$.
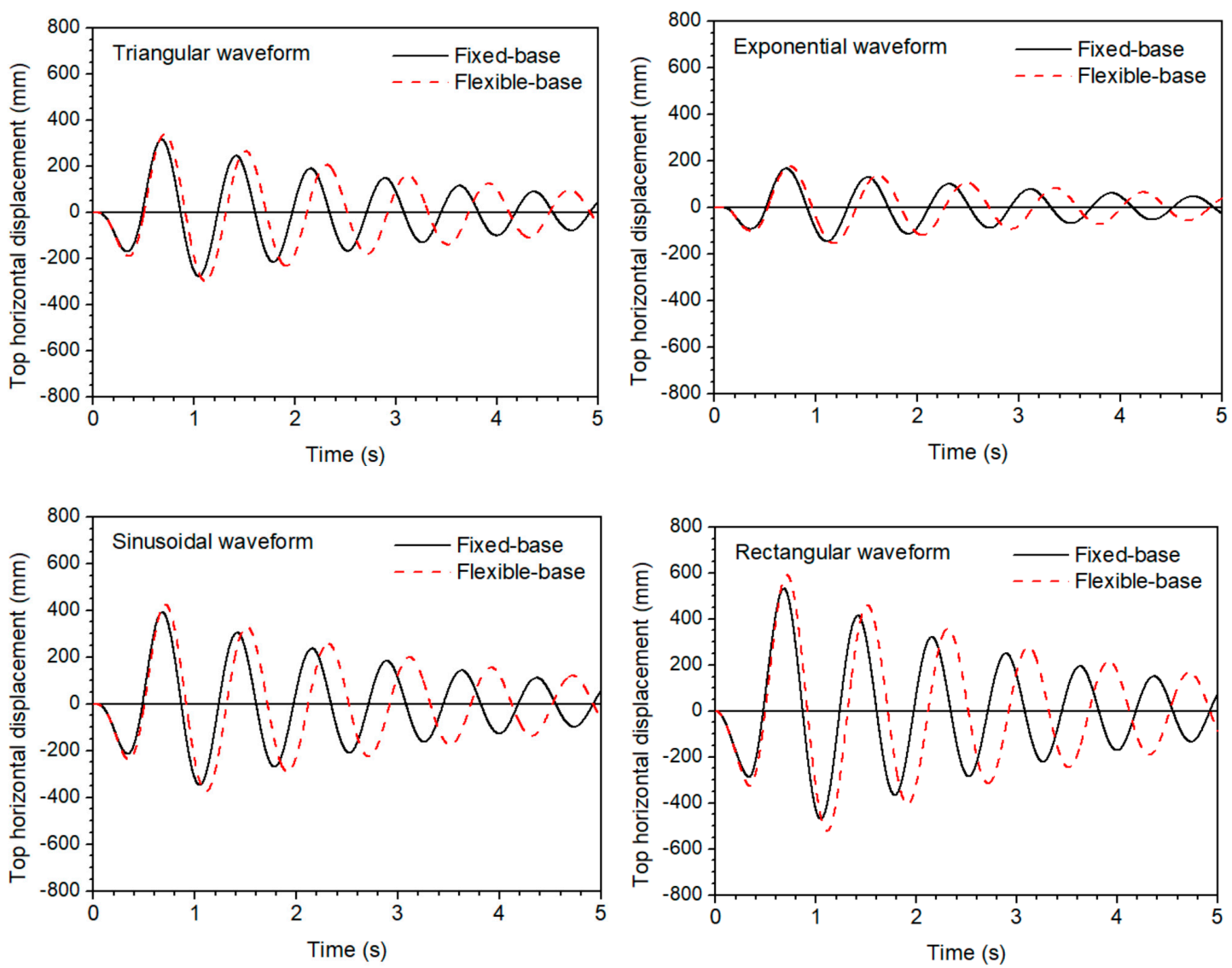

Figure 14. Time-history of horizontal displacement of OJP for rigid- and deformable soil.

The difference between these cases is obvious where the rectangular waveform appears to be the most intense while the exponential pulse appears to lead to the slightest results/response, for the above-mentioned specific load frequency. Furthermore, the flexibility of the soil appears to be important for the reliable assessment of offshore jacket platforms, taking into account that a soil-pile-platform model behaves differently in comparison with the platform that is founded on rigid soil.

\subsection{Nonlinear Analysis}

The inelastic response of OJP is investigated in this subsection. To generalize, the rectangular and triangular pulses are applied to rigid soil, considering load frequency $\omega=10 \mathrm{rad} / \mathrm{s}$ with various values of maximum Peak Ground Acceleration-PGA, to execute an incremental dynamic analysis. The corresponding results are shown in Figure 15. It is obvious that the higher the PGA, the more intense the response is in terms of deformation. 

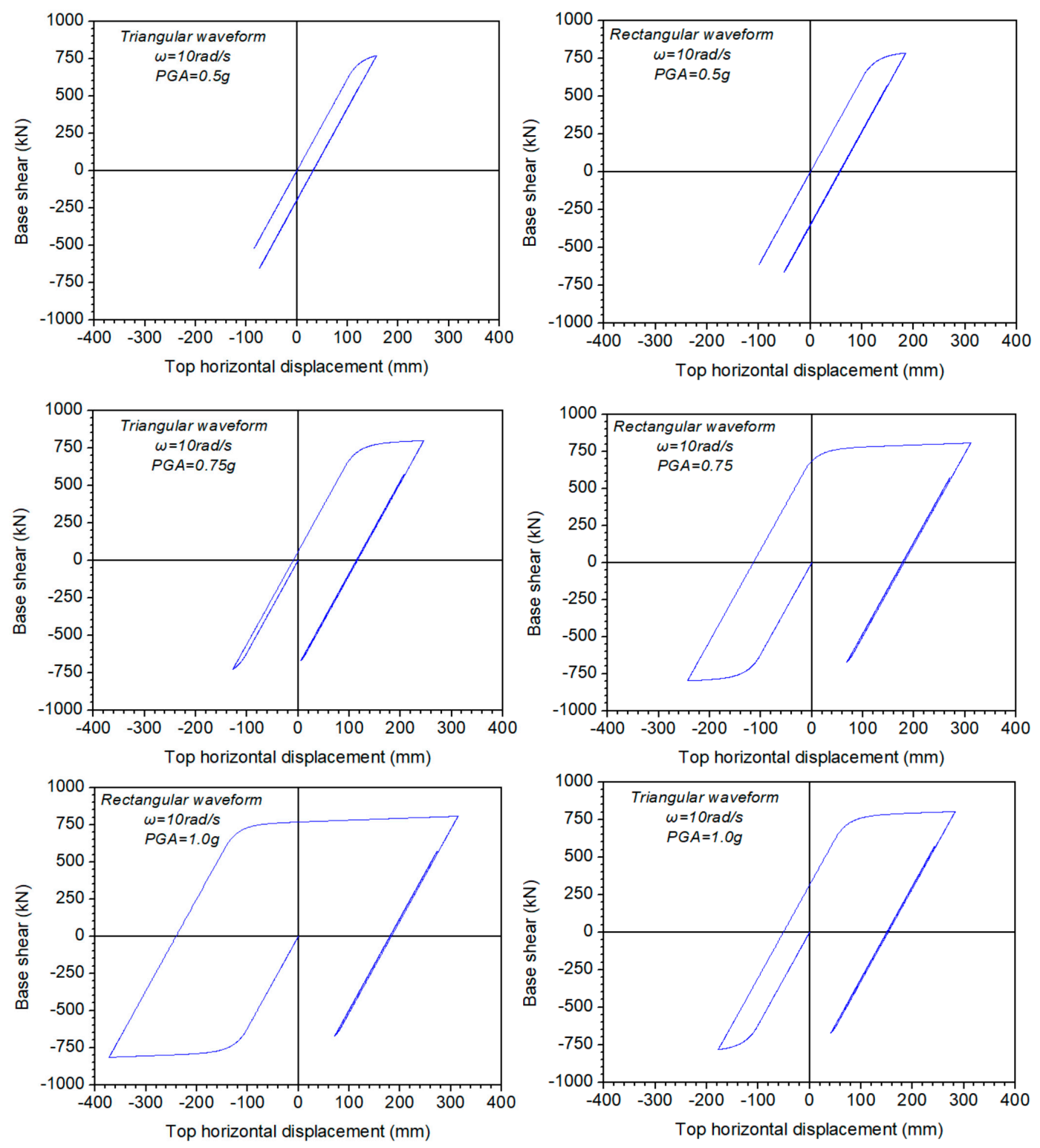

Figure 15. Top horizontal displacement vs. base shear for various PGAs.

\subsection{Small- and Large-Displacement Formulation}

The effects of geometric nonlinearities are investigated in this subsection. The aforementioned analysis results have been produced, assuming the small-displacement formulation of the equation of motion. However, to consider the large displacement formulation of the equation of motion, i.e., the geometric nonlinear phenomena including an unstable/buckling response [32,33], Figure 16 depicts the incremental dynamic analysis for the case of rigid soil and a sinusoidal pulse. Furthermore, Figure 17 shows the results for the case of rigid soil and a triangular pulse. It is obvious, due to the dynamic nonlinear buckling of the diagonal braces of the platform, the maximum load capacity of the offshore structure is much lower considering the large-displacement formulation in comparison with the small-displacement formulation for the equation of motion, i.e., ignoring geometric nonlinearities. Therefore, in any case, it is required to model reliably the overall response of the structural members, considering the whole set of nonlinearities-geometric and material. 


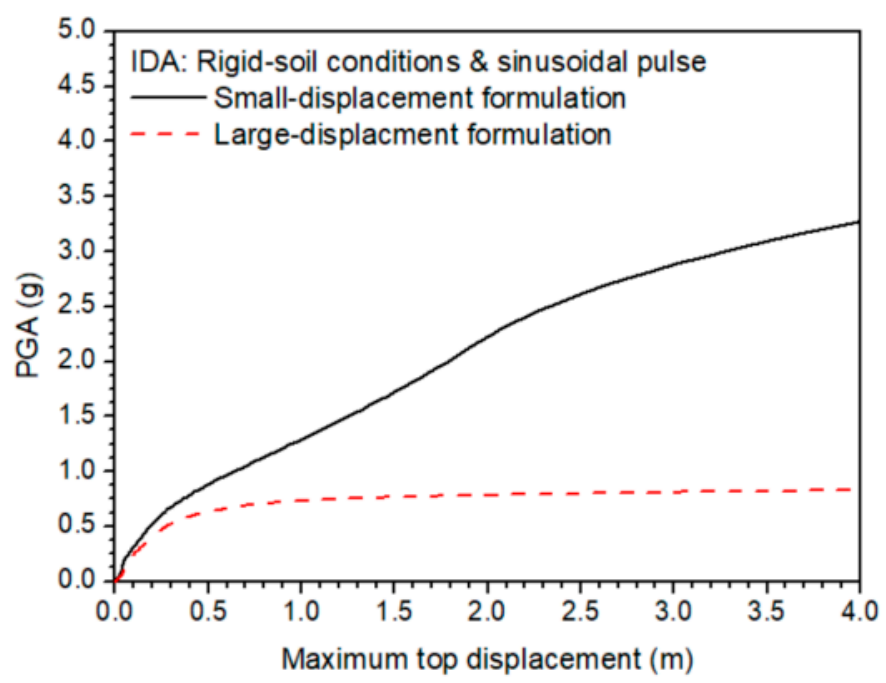

Figure 16. Incremental dynamic analysis considering and ignoring geometric nonlinearities. Rigid soil conditions with a sinusoidal pulse.

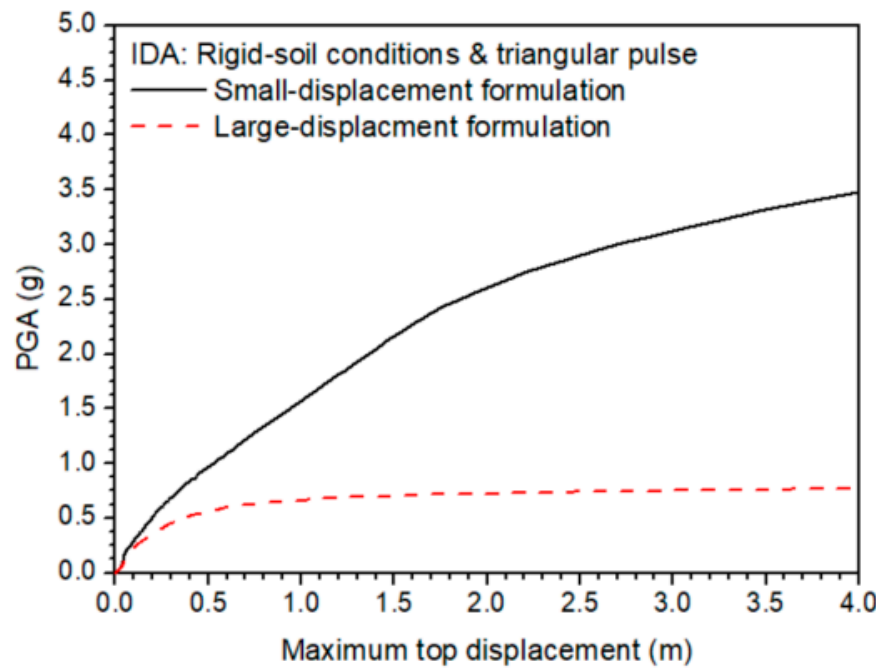

Figure 17. Incremental dynamic analysis considering and ignoring geometric nonlinearities. Rigid soil conditions with a sinusoidal pulse.

\subsection{The Effects of the Angle of Incident of Seismic Pulses on the Platforms' Dynamic Response}

This subsection examines the effects of the angle of incidence of seismic pulses in relation to the $X$-axis (Figure 7) on the dynamic response of platforms. Figure 18, for example, depicts the maximum top horizontal displacement for several incidence angles of seismic waves and for the whole gamut of pulses, examining the case of a soil-pile-platform inelastic system.

It is obvious that the incidence angle of seismic waves influences the overall (global) behavior of an offshore platform. 

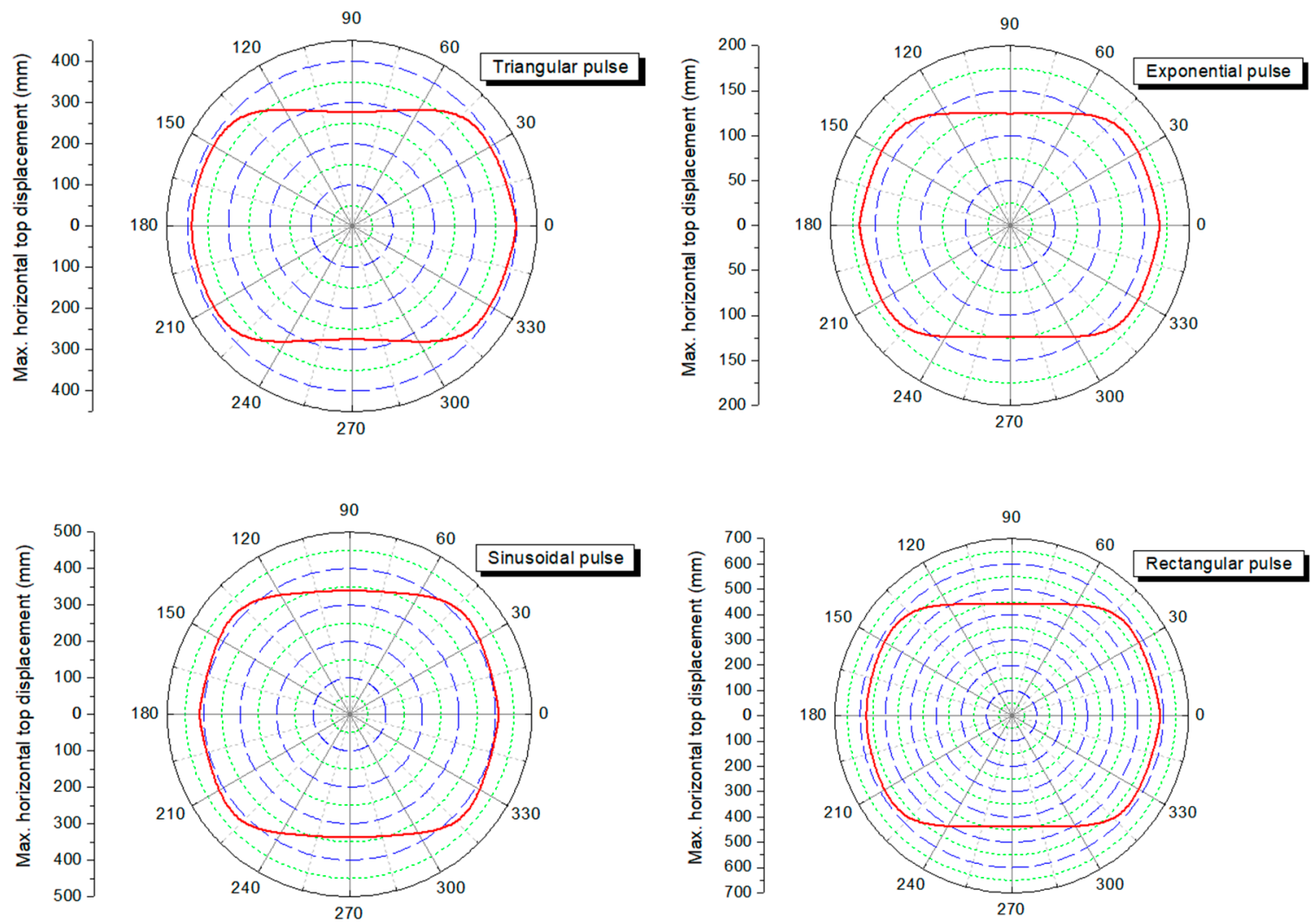

Figure 18. Influence of incidence angle of seismic waves on the maximum top horizontal displacement of a soil-pile-platform system.

\section{Conclusions}

This investigation examined the seismic safety and performance of three-dimensional jacket-type offshore structures under the action of pulse-type strong earthquakes. To examine the influence of a dynamic soil-pile-platform, two different models were investigated, one assuming rigid soil conditions and one for deformable soil. This study generated several important findings that are summarized in the following:

(1) Although this investigation considers only simplified pulses, its importance seems to be noteworthy taking into account that near-fault ground motions are frequently characterized by simple waveforms.

(2) The consideration of rigid soil strongly affects the response in comparison to the case of deformable soil, and the dynamic inelastic pile-soil-platform interaction should be taken into account. More specifically, the flexibility of the soil elongates the whole set of eigenperiods of platforms and, in most of the cases, it leads to higher values of maximum deformations in comparison with the case of fixed-based platforms.

(3) Each type of pulse under consideration led to different results, even in the case where the circular frequency and the maximum peak ground acceleration was identical in any case.

(4) When executing incremental dynamic analysis, it was found that geometric nonlinearity should be taken into account since their ignorance leads to a fictitious higher seismic performance and strength of platforms. More specifically, both the geometric nonlinearity of the soil and the diagonal braces, which lost their out-of-plane stability, leads to buckling-prone structures.

(5) The incidence angle of seismic waves appears to be a crucial parameter where, for some critical angles, the maximum deformation can be increased significantly in comparison to the ones corresponding to other, less crucial angles. 
(6) The aforementioned findings and conclusions can be generalized to other types of platforms and pulses than those examined, but more analyses and investigations will be required.

Author Contributions: All the Authors (F.K., G.P., N.P., K.E., I.N., G.H.) have in the same way contributed to the design, conception, and development of this study. The final version of the manuscript has been revised and accepted by all the Authors. All authors have read and agreed to the published version of the manuscript.

Funding: This research received no external funding.

Conflicts of Interest: The authors declare no conflict of interest.

\section{References}

1. Ji, C.Y.; Xue, H.Z.; Shi, X.H.; Gaidai, O. Experimental and numerical study on collapse of aged jacket platforms caused by corrosion or fatigue cracking. Eng. Struct. 2016, 112, 14-22. [CrossRef]

2. Nabavian, M.; Morshed, A. Extending life of fixed offshore installations by integrity management: A structural overview. In Proceedings of the Abu Dhabi International Petroleum Exhibition and Conference, Abu Dhabi, UAE, 1-4 November 2010; Society of Petroleum Engineers: Abu Dhabi, UAE, 2010.

3. Chen, J.Y.; Litton, R.; Ku, A.; Fraser, R.; Jeanjean, P. Seismic soil-structure interaction design considerations for offshore platforms. In Proceedings of the International Conference on Offshore Mechanics and Arctic Engineering, Busan, Korea, 19-24 June 2016; American Society of Mechanical Engineers: Busan, Korea, 2016; Volume 49927, p. V001T10A003.

4. El-Din, M.N.; Kim, J. Simplified seismic life cycle cost estimation of a steel jacket offshore platform structure. Struct. Infrastruct. Eng. 2017, 13, 1027-1044. [CrossRef]

5. Jahanitabar, A.A.; Bargi, K. Time-dependent seismic fragility curves for aging jacket-type offshore platforms subjected to earthquake ground motions. Struct. Infrastruct. Eng. 2018, 14, 192-202. [CrossRef]

6. Konstandakopoulou, F.D.; Papagiannopoulos, G.A.; Pnevmatikos, N.G.; Hatzigeorgiou, G.D. Seismic hazard assessment of offshore platforms. Int. J. Civ. Environ. Eng. 2019, 13, 272-276.

7. Konstandakopoulou, F.D.; Evangelinos, K.I.; Nikolaou, I.E.; Papagiannopoulos, G.A.; Pnevmatikos, N.G. Seismic analysis of offshore platforms subjected to pulse-type ground motions compatible with European Standards. Soil Dyn. Earthq. Eng. 2020, 129, 105713. [CrossRef]

8. Elsayed, T.; El-Shaib, M.; Gbr, K. Reliability of fixed offshore jacket platform against earthquake collapse. Ships Offshore Struct. 2016, 11, 167-181. [CrossRef]

9. Som, A.; Das, D. Seismic vibration control of offshore jacket platforms using decentralized sliding mode algorithm. Ocean Eng. 2018, 152, 377-390. [CrossRef]

10. Park, M.S.; Koo, W.; Kawano, K. Dynamic response analysis of an offshore platform due to seismic motions. Eng. Struct. 2011, 33, 1607-1616. [CrossRef]

11. Ajamy, A.; Asgarian, B.; Ventura, C.E.; Zolfaghari, M.R. Seismic fragility analysis of jacket type offshore platforms considering soil-pile-structure interaction. Eng. Struct. 2018, 174, 198-211. [CrossRef]

12. Zarrin, M.; Asgarian, B.; Abyani, M. Probabilistic seismic collapse analysis of jacket offshore platforms. J. Offshore Mech. Arct. Eng. 2018, 140, 031601. [CrossRef]

13. Abyani, M.; Bahaari, M.R.; Zarrin, M.; Nasseri, M. Effects of sample size of ground motions on seismic fragility analysis of offshore jacket platforms using Genetic Algorithm. Ocean Eng. 2019, 189, 106326. [CrossRef]

14. Lotfollahi-Yaghin, M.A.; Ahmadi, H.; Tafakhor, H. Seismic responses of an offshore jacket-type platform incorporated with tuned liquid dampers. Adv. Struct. Eng. 2016, 19, 227-238. [CrossRef]

15. Minasidis, G.; Hatzigeorgiou, G.D.; Beskos, D.E. SSI in steel frames subjected to near-fault earthquakes. Soil Dyn. Earthq. Eng. 2014, 66, 56-68. [CrossRef]

16. Hatzigeorgiou, G.D.; Pnevmatikos, N.G. Maximum damping forces for structures with viscous dampers under near-source earthquakes. Eng. Struct. 2014, 68, 1-13. [CrossRef]

17. Konstandakopoulou, F.; Hatzigeorgiou, G. Constant-ductility inelastic displacement, velocity and acceleration ratios for systems subjected to simple pulses. Soil Dyn. Earthq. Eng. 2020, 131, 106027. [CrossRef]

18. Zhao, C.; Valliappan, S. Incident $P$ and SV wave scattering effects under different canyon topographic and geological conditions. Int. J. Numer. Anal. Methods Geomech. 1993, 17, 73-94. [CrossRef] 
19. Hatzigeorgiou, G.D. Damping modification factors for SDOF systems subjected to near-fault, far-fault and artificial earthquakes. Earthq. Eng. Struct. Dyn. 2020, 39, 1239-1258. [CrossRef]

20. Konstandakopoulou, F.D.; Hatzigeorgiou, G.D. Water and wastewater steel tanks under multiple earthquakes. Soil Dyn. Earthq. Eng. 2017, 100, 445-453. [CrossRef]

21. Baker, J.W. Quantitative classification of near-fault ground motions using wavelet analysis. Bull. Seismol. Soc. Am. 2007, 97, 1486-1501. [CrossRef]

22. Champion, C.; Liel, A. The effect of near-fault directivity on building seismic collapse risk. Earthq. Eng. Struct. Dyn. 2012, 41, 1391-1409. [CrossRef]

23. He, W.L.; Agrawal, A.K. Analytical model of ground motion pulses for the design and assessment of seismic protective systems. J. Struct. Eng. 2008, 134, 1177-1188. [CrossRef]

24. Christidis, A.A.; Dimitroudi, E.G.; Hatzigeorgiou, G.D.; Beskos, D.E. Maximum seismic displacements evaluation of steel frames from their post-earthquake residual deformation. Bull. Earthq. Eng. 2013, 11, 2233-2248. [CrossRef]

25. Pnevmatikos, N.G.; Hatzigeorgiou, G.D. Damage detection of framed structures subjected to earthquake excitation using discrete wavelet analysis. Bull. Earthq. Eng. 2017, 15, 227-248. [CrossRef]

26. Carr, A.J. RUAUMOKO-Inelastic Dynamic Analysis Program; Department of Civil Engineering, University of Canterbury: Christchurch, New Zealand, 2008.

27. Ramberg, W.; Osgood, W.R. Description of Stress-Strain Curves by Three Parameters; Technical Note No. 902, National Advisory Committee for Aeronautics; NASA: Washington, DC, USA, 1943; p. 4.

28. American Petroleum Institute (API). RP2A-WSD AP: Recommended Practice for Planning, Designing and Constructing Fixed Offshore Platforms; API: Washington, DC, USA, 2007.

29. Boulanger, R.W.; Curras, C.J.; Kutter, B.L.; Wilson, D.W.; Abghari, A. Seismic soil-pile-structure interaction experiments and analyses. J. Geotech. Geoenviron. Eng. 1999, 125, 750-759. [CrossRef]

30. Remennikov, A.; Walpole, W.R. Analytical prediction of seismic behaviour for concentrically-braced steel systems. Earthq. Eng. Struct. Dyn. 1997, 26, 859-874. [CrossRef]

31. Al-Bermani, F.G.A.; Li, B.; Zhu, K.; Kitipornchai, S. Cyclic and seismic response of flexibly jointed frames. Eng. Struct. 1994, 16, 249-255. [CrossRef]

32. Bathe, K.J. Finite Element Procedures, TBS, 1st ed.; Prentice Hall: Upper Saddle River, NJ, USA, 2007.

33. Li, Z.; Hatzigeorgiou, G.D. Seismic damage analysis of RC structures using fiber beam-column elements. Soil Dyn. Earthq. Eng. 2012, 32, 103-110. [CrossRef]

Publisher's Note: MDPI stays neutral with regard to jurisdictional claims in published maps and institutional affiliations.

(C) 2020 by the authors. Licensee MDPI, Basel, Switzerland. This article is an open access article distributed under the terms and conditions of the Creative Commons Attribution (CC BY) license (http://creativecommons.org/licenses/by/4.0/). 